\title{
Adverse drug reactions observed in treatment of gastro intestinal and respiratory tract infections: a prospective analysis
}

\section{Laxmipathi Kodam ${ }^{1}$, Naveen Kumar Tamma ${ }^{2} *$, Janardhan Marupaka ${ }^{1}$, Srinivasu Karedla ${ }^{2}$}

\author{
${ }^{1}$ Department of Pharmacology, Rajiv Gandhi Institute of Medical Sciences, Adilabad, Telangana, India \\ ${ }^{2}$ Department of Pharmacology, Mahavir Institute of Medical Sciences, Vikarabad, Telangana, India
}

Received: 19 October 2019

Revised: 02 December 2019

Accepted: 03 December 2019

\section{*Correspondence:}

Dr. Naveen Kumar Tamma,

Email: doctornaveen1@rediffmail.com

Copyright: (c) the author(s), publisher and licensee Medip Academy. This is an open-access article distributed under the terms of the Creative Commons Attribution Non-Commercial License, which permits unrestricted non-commercial use, distribution, and reproduction in any medium, provided the original work is properly cited.

\begin{abstract}
Background: The aim of the study was to observe common adverse drug reactions in treatment of gastro intestinal and respiratory tract infections in a tertiary care hospitals.

Methods: A prospective observational study was conducted by Departments of Pharmacology for a period of one year from prescriptions and case sheets of medical record section. Adverse drug reaction reporting forms and alert cards were used for reporting.

Results: The drugs most commonly used for gastrointestinal tract and respiratory diseases are tablets norflox $400 \mathrm{mg}$ norflox-tz, taxim $200 \mathrm{mg}$, IV amikacin and IV amoxicillin $(500 \mathrm{mg}$ ) and clavulanic acid (125 mg) combination. Systems affected by use of above drugs were skin and gastrointestinal tract. Urticaria on skin, abdominal pain, itching in genital area, ulcer on oral mucosa are the common adverse drug reactions observed.

Conclusions: Drugs used for common gastrointestinal tract and respiratory tract infections alert cards should be issued to patients when prescribing and adverse drug reactions should be reported to higher centres. Brand names causing adverse reactions should be monitored regularly and their further usage should be based on signals from other centres. All tertiary care hospitals should have antimicrobial guidelines policy to reduce adverse drug reactions.
\end{abstract}

Keywords: Health care professionals, Adverse drug reactions, Respiratory tract infections

\section{INTRODUCTION}

Pharmacovigilance is defined by the World Health Organization (WHO) as "the science and activities relating to the detection, assessment, understanding and prevention of adverse effects or any other possible drug related problems." Most countries in the world have established adverse drug reaction (ADR) reporting.

ADRs have been a global problem of major concern, causing both morbidity and mortality, affecting both children and adults with varying magnitude.
When a drug is marketed little is known about its safety in clinical use because only about 1500 patients are likely to have been exposed to it. Thus drug safety assessment should be considered an integral part of everyday clinical practice since detection and diagnosis often depend on clinical acumen.

A number of complexities interfere with recognition and reporting of ADRs in nearly all cases the patient is already ill and the specific event could result of the underlying disease rather than medication, many patients especially those hospitalized or in the institutions are taking multiple medications, there is lack of practical 
definition to what to collect and many reports lack a standard approach to reporting and even clinical pharmacologist with an interest in ADRs often cannot agree on whether specific event was drug related or which drug was the causative agents. ${ }^{1,2}$

ADR reporting programs on an institutional basis can provide valuable information about potential problems in drug usage in that institution.

There is a need to inform the treating doctors about the importance of observing for ADR following pharmacotherapy, recording them meticulously and reporting them to the concerned authority. This practice will prove to be very valuable in making the drug therapy safer and rational. Setting up of ADR monitoring centers at a more regional or hospital level and integrating them with a sound network can reveal unusual or rare ADRs prevalent in Indian population.

Prevention of adverse effects to drugs can be minimized but not altogether eliminated by observing the following practice: avoid all inappropriate use of drugs in context to patient clinical condition, use appropriate dose, route and frequency of drug administration, elicit and take in to consideration previous history of drug reactions, rule out possibility of drug reactions when more than one drug is prescribed. $^{3}$

The objectives of the present study was to examine the prevalence of ADRs for drugs used in treatment of common gastro intestinal and respiratory tract infections and reporting of incidence that helps to improve the clinical condition of patients and reduce cost of treatments.

\section{METHODS}

The present study was prospective study conducted by department of pharmacology in Rajiv Gandhi Institute of
Medical Sciences, Adilabad and Mahavir Institute of Medical Sciences, Vikarabad, Telangana a tertiary care hospitals after approval by the institutional ethical committee.

The study was done for period of one year from May 2018 to April 2019. Patients of either sex and any age group were include in the study sex and exclusion criteria are suspected ADRs due to drug overdose.

Data was collected from out patient's prescriptions and case sheets of inpatient departments. Adverse drug reporting forms and alert cards were used for the conduct of study.

\section{Statistical analysis}

Statistical analysis was done by SPSS software version.

\section{RESULTS}

A total of 52 ADRs were identified during one year of study from May 2018 to April 2019. Majority of ADRs occurred in age group of 20-75 years, more common in geriatric age and patients receiving monotherapy and combination therapy.

In Table 2, general medicine (35) reported maximum number of ADRs followed by dermatology (10), pulmonology (5) and casuality (2). ADRs were reported following single and combination therapy.

Risk factors for gastrointestinal and respiratory tract infections identified in this study are poor feeding practice, overcrowding, malnutrition, poor socioeconomic status,

Table 1 describes common adverse reactions observed due to use of brand name for gastrointestinal and respiratory tract infections.

Table 1: Drugs and type of ADRs.

\begin{tabular}{|c|c|c|c|}
\hline Drugs & ADR & No of patients & $\%$ \\
\hline $\begin{array}{l}\text { Norflox and tinidazole tablet } \\
\text { combination. }\end{array}$ & Mucosal eruptions over mouth & 10 & 19.2 \\
\hline Norflox tablets & Urticaria rash over trunk and upper and lower limbs. & 8 & 15.3 \\
\hline Taxim $200 \mathrm{mg}$ tablet & Urticarial rash all over body. & 6 & 11.5 \\
\hline $\begin{array}{l}\text { Inj amoxicillin }(500 \mathrm{mg}) \text { and } \\
\text { clavulanic acid }(125 \mathrm{mg}) \text { combination }\end{array}$ & $\begin{array}{l}\text { Itching in genital area and ulcer on genitalia and } \\
\text { oral mucosa. }\end{array}$ & 4 & 7.6 \\
\hline Metrogyl suspension & Steven johnsons syndrome & 8 & 15.3 \\
\hline Anti TB drugs H75, R150, E 2 & $\begin{array}{l}\text { Eythematous rash with pustules over body surface } \\
\text { area. }\end{array}$ & 5 & 9.6 \\
\hline Vitamin B12 injection & $\begin{array}{l}\text { Itching and burning sensation all over body, } \\
\text { swelling of face and tongue }\end{array}$ & 3 & 5.7 \\
\hline Amikacin IV & Severe skin rash at the site of injection & 4 & 7.6 \\
\hline Tab betamethasone one year usage & Abdominal pain & 4 & 7.6 \\
\hline
\end{tabular}


Table 2: ADRs reported from clinical departments.

\begin{tabular}{|l|c|}
\hline Department & No. of ADRs \\
\hline General medicines & 35 \\
\hline Dermatology & 10 \\
\hline Pulmonology & 5 \\
\hline Casualty & 2 \\
\hline
\end{tabular}

\section{DISCUSSION}

Spontaneous reporting of ADRs to the regional monitoring centre or National monitoring centre via the ADR reporting form is crucial for safety surveillance of the marketed drugs. ${ }^{4,5}$

Major problem in India is under reporting of ADRs due to lack of proper system of pharmaco-vigilance. Ability to anticipate and prevent ADRs can be facilitated by establishment of standard approaches by all health care professionals.

In Table 1, the drugs most commonly used for gastrointestinal tract and respiratory diseases are tablets norflox $400 \mathrm{mg}$, norflox-tz, taxim $200 \mathrm{mg}$, IV amikacin and $\mathrm{Inj}$ amoxicillin (500 $\mathrm{mg}$ ) and clavulanic acid (125mg) combination. Systems affected with use of above drugs are skin and gastrointestinal tract. The results were comparable with international study conducted by suhetal. $^{6}$

Cephalosporins and fluoroquinolones were the commonly used antibiotics in the study and the reported ADRs were also more in these drug classes. A study conducted by Stavreva et al also revealed the predominance of cephalosporins whereas fluoroquinolones were most accounted in a study conducted by Hussain et al. ${ }^{7,8}$

Causality assessment was done by using Naranjo scale and severity of ADRs by modified Hartwig and Siegal scale. The severity of 52 cases of ADRs showed $32 \%$ as possible (norflox and tinidazole combination, metrogyl suspension, tab betamethasone and injections of vitamin B12) and the remaining drugs $68 \%$ as propable. In 18 cases (norflox and tinidazole combination and metrogyl suspension) the ADRs was managed by withdrawl of drug and specific treatment given. In 34 patients the dose of drug was altered and patients recovered from the reaction. The suspected ADRs were reported to the regional pharmacovigilance centre through on line and by mailing.

ADRs observed with use of norflox and its combination are mucosal eruptions over mouth, urticaria rash over trunk, upper and lower limbs compared to previous study by Roberge et al, Theoharides etal and Ratikanta et al. ${ }^{9-11}$ Hypoglycemia caused by some fluoroquinolones is well established in literature. Published reports are available for ciprofloxacin, gatifloxacin, and clinafloxacin. Hypoglycemic stress can activate the release of corticotrophin-releasing hormone (CRH) by postganglionic sympathetic neurons as well as the hypothalamus. CRH-stimulated mast cell degranulation could lead to urticaria. ${ }^{9-11}$

Cefotaxim use has caused urticarial rash all over body which was comparable to review of literature from Petz and from management of rash by Kim et al studies. ${ }^{12,13}$

Itching in genital area and ulcer on genitalia and oral mucosa with use of inj amoxicillin (500 mg) and clavulanic acid (125 mg) combination. ${ }^{12,13}$

Steven johnsons syndrome with use of metrogyl suspension as reports from Chen et al and from Bolognia et al. ${ }^{14,15}$

Eythematous rash with pustules over body surface area with use of antitubercular drugs as done by studies done by Sameeretal and Dhingra et al. ${ }^{16,17}$

Vitamin B12 injection has caused itching and burning sensation all over body, swelling of face and tongue as reports from Rajendran et al and James et al. ${ }^{18,19}$

Amikacin IV has resulted in severe skin rash at the site of injection which was comparable to studies by Suken et al and Bensaid et al. ${ }^{20,21}$

Long term use of corticosteroid tab betamethasone few patients has complained of abdominal pain. The results were comparable to Mulchand et al and Conn et al. ${ }^{22,23}$

ADR forms should be available in outpatient, inpatient departments and drug alerts cards should be issued to patients for reporting possible adverse effects. Drugs causing adverse reaction by brand names should be reported to manufacturer and through vigiflow sent to higher centres. If the reactions are severe in nature can be withdrawn from market based on signals from other hospitals. Antimicrobial guidelines common to all tertiary care hospitals should be framed to reduce ADRs, and economic burden on patient. Regular sensitization of health care professionals regarding importance of ADRs can reduce reactions due to drugs.

\section{CONCLUSION}

While using drugs for common gastrointestinal tract and respiratory tract infections treating doctors should issue alert cards to patients and ADRs should be reported to higher centres. Brand names causing adverse reactions should be monitored regularly and their further usage should be based on signals from other centres. All tertiary care hospitals should have antimicrobial guidelines policy to reduce ADRs and economic burden on patients.

\section{Funding: No funding sources}

Conflict of interest: None declared

Ethical approval: The study was approved by the Institutional Ethics Committee 


\section{REFERENCES}

1. Karch FF, Smith Cl, Kerznel B, Mazullo JM, Weintraub M, Lasagna L. Adverse drug reactions. Clin Pharmacolot Ther. 1976;19:489-92.

2. Koch-Weser J, Sellers EM, Zacet R. The ambiguity of adverse drug reaction. Eur J Clin Pharmacol. 1977;11:75-8.

3. Tripathi KD. Adverse drug effects. Essentials of Medical Pharmacology. 8th ed. New Delhi: 2019: 9394.

4. Bateman DN, Sanders GL, Rawlins MD. Attitudes to adverse drug reporting in the Northern Region. Br J Clin Pharmacol. 1992;34(5):421-6.

5. Patel KJ, Kedia MS, Bajpai D, Mehta SS, Kshirsagar NA, Gogtay NJ, et al. Evaluation of the prevalence and economic burden of adverse drug reactions presenting to the medical emergency department of a tertiary referral centre: a prospective study. BMC Clin Pharmacol. 2007;28:7-8.

6. Suh DC, Woodall BS, Shin SK, Hermes-De Santis ER. Clinical and economic impact of adverse drug reactions in hospitalized patients. Ann Pharmacother. 2000;34(12):1373-9.

7. Stavreva G, Pendicheva D, Pandurska A, Marev R. Detection of adverse drug reactions to antimicrobial drugs in hospitalized patients. Trakia $\mathbf{J}$ Sci. 2008;6(1):7-9.

8. Mohammed MH, Kundlik G, Ranju P, Shahina SS. Incidence of adverse drug reactions in a tertiary care hospital: a systematic review and meta-analysis of prospective studies. Der Pharmacia Lettre. 2010;2(3):358-68.

9. Roberge RJ, Kaplan R, Frank R, Fore C. Glyburideciprofloxacin interaction with resistant hypoglycemia. Ann Emerg Med. 2000;36:160-3.

10. Theoharides TC, Singh LK, Boucher W, Pang X, Letourneau R, Webster E, Chrousos G. Corticotropin-releasing hormone induces skin mast cell degranulation and increased vascular permeability, a possible explanation for its proinflammatory effects. Endocrinology. 1998;139(1):403-13.

11. Ratikanta T, Pradhan MR. A rare case of recurrent fixed drug eruption and lip edema due to norflox and tinidazole fixed dose combination. Int Res J Pharm. 2015;6(3):204-5.

12. Petz LD. Immunologic cross reactivity between penicillins and cephalosporins: A review. J Infect Dis. 1978; 137:74-9.
13. Kim MH, Lee JM. Diagnosis and management of immediate hypersensitivity reactions to cephalosporins. Allergy Asthma Immunol Res. 2014;6:485-95.

14. Chen KT, Twu SJ, Chang HJ, Lin RS. Outbreak of stevens-Johson syndrome/toxic epidermal necrolysis associated with mebendazole and metronidazole use among Filipino labourers in Taiwan. Am J Public Health. 2003;93(3):489-92.

15. Stevens-Johnson Syndrome Toxic Epidermal Necrosis. In: Bolognia JL, Jorizzo JL, Rapini RP, eds. Dermatology. 2nd ed. Amsterdam: Elsevier Limited; 2008: 291-300.

16. Sameer G, Paljor HP, Rohit M, Pankaj G. Erythema multiforme due to antitubercular drugs. Lung India. 2011;28(1):76-7.

17. Dhingra VK, Rajpal S, Aggarwal N,Aggarwal JK, Shadab K, Jain SK. Adverse drug reactions observed during DOTS. J Commun Dis. 2004;36:251-9.

18. Rajendran K, Matthew JMN. Cutaneous lesions and vitamin B12 deficiency. Can Fam Physician. 2008;54(4):529-32.

19. James J, Warin RP. Sensitivity to cyanocobalamin and hydroxocobalamin. Br Med J. 1971;2:262.

20. Suken S, Sujay S, Abhisek J. Amikacin-triggered anaphylaxis: Should we go for skin test? J Pharmacol Pharmacother. 2014;5(1):53-4.

21. Bensaid B, Rozieres A, Nosbaum A, Nicolas JF, Berard F. Amikacin-induced drug reaction with eosinophilia and systemic symptoms syndrome: Delayed skin test and ELISPOT assay results allow the identification of the culprit drug. J Allergy Clin Immunol. 2012;130:1413-4.

22. Mulchand S, Bhupesh G, Dhanshree P, Aparna K. Assessment of drug utilization pattern of steroids in a district general hospital in Amravati region. Res Results Pharma. 2019;5(2):57-64.

23. Conn HO, Poynard T. Corticosteroids and peptic ulcer: meta-analysis of adverse events during steroid therapy. J Intern Med. 1994;236(6):619-32.

Cite this article as: Kodam L, Tamma NK, Marupaka J, Karedla S. Adverse drug reactions observed in treatment of gastro intestinal and respiratory tract infections: a prospective analysis. Int J Basic Clin Pharmacol 2020;9:134-7. 